\title{
Atratividade e preferencia de lagartas do curuquerê por genótipos de algodoeiro
}

\author{
Jasmine Martins Rodrigues ${ }^{1 *}$, Francisco Sales Fernandes², Thiele da Silva Carvalho ${ }^{3}$
}

\begin{abstract}
RESUMO: Alabama argillacea é uma importante praga desfolhadora da cultura do algodoeiro no Brasil e em países produtores como Austrália, Burkina, China, Índia entre outros. Ela acarreta destruição da área foliar, comprometendo taxas fotossintéticas e a produtividade da pluma e do caroço. Objetivou-se estudar a atratividade e preferência alimentar de A. argillacea a genótipos de algodoeiro. Avaliou-se a atratividade e preferencia alimentar de lagartas do curuquerê em teste de chance de escolha nos genótipos TB 87, TB 85, TB 91 e Grandless. O delineamento experimental foi blocos ao acaso, com quatro tratamentos, 10 repetições e quatro horários de avaliação (15 minutos, 45 minutos, 1 e 2 horas). O genótipo de algodoeiro menos preferido e atrativo para alimentação é o Grandless enquanto que as cultivares TB 87, TB 85, e TB 91 são mais atacadas pelas lagartas. Dentre os genótipos avaliados, a Grandless apresenta menos susceptibilidade em mesmas condições de ataque.
\end{abstract}

Palavras-chave: Alabama argillacea, inseto-praga, Gossypium hirsutum.

\section{Attractiveness and food preference of leafworm to cotton genotypes}

\begin{abstract}
Alabama argillacea is an important cotton defoliating pest in Brazil, Australia, Bukina, China and India. This pest can cause loss in cotton leaf area, committing photosynthetic rates and productivity of feather and cotton seed. The objective with this paper was to study the attractiveness and food preference by A. argillacea to cotton genotypes. The attractiveness and food preference of A. argillacea were evaluated in a multiple choice test. The genotypes used were TB 87, TB 85, TB 91 and Grandless. The random block experimental design with four treatments, 10 replicates and four times of observation (15 and 45 minutes, 1 and 2 hours) was used in the experiment. Our results showed that Grandless genotype was less attractiveness and preferred for feeding by leaf worm. On the other hand, the genotypes TB 87, TB 85 and TB 91 are more attacked than Grandlessone. In the same experiment condition we can conclude that the Grandless genotype showed less susceptible than the other one.
\end{abstract}

Keywords: Alabama argillacea, insect-pest, Gossypium hirsutum.

\section{INTRODUÇÃO}

A cultura do algodão Gossypium hirsutum L., (Malvaceae) é de grande expressão socioeconômica para os setores primário e secundário do Brasil, entretanto a ocorrência de pragas constitui-se um dos fatores limitantes para a sua exploração agrícola e comercial. Dentre as pragas, o curuquerê (Alabama argillacea Huebner, 1818) (Lepidoptera: Noctuidae) tem se destacado como principal inseto desfolhador da cultura no Brasil (EMBRAPA ALGODÃO, 2003); (CARVALHO, SOUZA, 2002). O seu aparecimento em áreas de cultivo está associado a períodos de estiagem após precipitações pluviais (ALMEIDA et al., 2013). Uma vez presente em alta densidade, a espécie compromete a capacidade fotossintética das plantas, sendo os últimos três ínstares larvais responsáveis pela maior parte das desfolhas. A. argillacea ataca o limbo foliar, nervuras e pecíolos, consumindo em média $66 \mathrm{~cm}^{2}$ da folha e, dependendo da época de ataque, pode ocasionar maturação precoce das maçãs e paralisação da frutificação, resultando na redução da produção (GALLO et al., 2002); (MIRANDA et al., 2015).

Como medida de controle convencional da $A$. argillacea, têm-se utilizado basicamente inseticidas químicos. Estes em curto prazo favorecem a redução de pragas agrícolas, todavia em longo prazo, podem propiciar resistência dos insetos, além de ocasionarem desequilíbrio ambiental. Na literatura existem registros de antibiose do algodoeiro ao ataque do curuquerê (LARA, 1991); (LARA et al., 1999); (FERREIRA, LARA, 1999); (SANTOS, BOIÇA-JÚNIOR, 2001), em resposta a ação de aldeídos-terpenos encontrados, como gossipol, heliocidas e hemigossipolone, sobre às larvas de várias espécies de lepidópteros (LARA, 1991); (MACEDO et al., 2007) e relatos de fatores como pilosidade e nectários atuando no comportamento de lepidópteros (LARA, 1991). Há também relatos de que $A$. argillacea quando alimentadas com folhas

\footnotetext{
Recebido em 11/06/2018; Aceito para publicação em 09/08/2019

${ }^{1}$ Universidade Federal Rural de Pernambuco

2 Universidade de São Paulo

${ }^{3}$ Universidade Estadual da Paraíba

*E-mail: jasmine.rodrigues@ufrpe.br
} 
cotiledonares, contendo ou não gossipol, apresenta taxas de sobrevivência semelhantes nestas cultivares, sendo maiores do que as observadas no desenvolvimento de outras lagartas generalistas (MONTANDON et al., 1986). De acordo com Mcauslane et al. (1997), o efeito do gossipol foi deterrente para lagartas de primeiros ínstares que consumiram em maior quantidade folhas desprovidas de gossipol (89\%), atuando o gossipol como um cairomônio, em prol do hospedeiro.

Apesar de Lara et al. (1999), terem verificado menos preferência de larvas do terceiro instar da $A$. argillacea pelos genótipos com efeito antibiótico, T 953 13-4-2 (2,95 mg) e CNPA 9211-31 (4,60 mg), informações sobre a preferencia alimentar deste inseto nos genótipos TB87, TB85, TB91 e Grandless são incipientes. $O$ presente trabalho teve por objetivo avaliar a atratividade e preferência alimentar de A. argillacea a diferentes genótipos de algodoeiro.

\section{MATERIAL E MÉTODOS}

O trabalho foi conduzido no Laboratório de Entomologia da Embrapa Algodão, Campina Grande, Paraíba, Brasil, localizados a $7^{\circ} 13$ ' $50^{\prime}$ S de latitude e $35^{\circ} 52^{\prime} 52^{\prime}$ ' W de longitude, em Janeiro de 2016.

As linhagens de algodoeiro, Gossypium hirsutum, TB 85, TB 87 e TB 91 foram originadas da geração F2, a partir do cruzamento da linhagem PNH3 e outra linhagem oriunda do cruzamento entre a cultivar Stoneville 213 com raças silvestres de algodoeiros e codificadas por $\mathrm{T}-277, \mathrm{~T}-326$ e $\mathrm{T}$ 1180 (CARVALHO et al., 1996).

Testes de preferência, deslocamento e consumo de A. argillacea foram realizados. A preferência para alimentação de $A$. argillacea foi avaliada em horários distintos e consistiu de testes com chance de escolha. A avaliação do deslocamento de $A$. argillacea foi realizada duas horas após liberação de insetos e também consistiu de testes com chances de escolhas. Discos foliares foram escaneados antes da oferta e duas horas após a exposição dos insetos no bioensaio. Nos testes de preferencia, utilizou-se o delineamento experimental em dez blocos ao acaso, quatro genótipos de algodoeiro $(\mathrm{T} 1=\mathrm{TB} 87 ; \mathrm{T} 2=$ $\mathrm{TB} 85 ; \mathrm{T} 3=\mathrm{TB} 91$ e $\mathrm{T} 4=$ Grandless), quatro horários de avaliação (15 minutos, 45 minutos, 1 e 2 horas) e dez repetições. Na avaliação do consumo alimentar e deslocamento dos insetos, o mesmo delineamento foi utilizado, exceto os horários de observação. A parcela consistiu de uma placa de Petri de $14,5 \mathrm{~cm}$ de diâmetro por $2 \mathrm{~cm}$ de altura, contendo em seu interior um disco de papel filtro de $14 \mathrm{~cm}$ de diâmetro com quatro discos foliares de algodão de cada linhagem $(4,5 \mathrm{~cm})$, posicionados de forma equidistante entre si e nas bordas do disco. As folhas foram coletadas em campo, na parte apical da planta, aos 120 dias após a emergência. No centro de cada placa de Petri (bloco) foram liberadas dez lagartas de quarto instar provenientes de criação.

A normalidade (teste Shapiro Wilk) e homogeneidade (teste Hatley) dos dados foram verificadas. O PROC GLM do SAS (Statistical Analysis System, 2006) bem como o teste Friedman, Bonferroni e lsmean $(P=0,05)$ foram utilizados para comparar os ranks.

\section{RESULTADOS E DISCUSSÕES}

O rank para o tempo de exposição $\left(\mathrm{F}_{3,135}=0.06\right.$, $P=0.9797$ ) ou a ausência de interação envolvendo o tempo e os tratamentos $\left(\mathrm{F}_{9,135}=0.04, P=1.0000\right)$ indica que comportamentos alimentares de $A$. argillacea após 15, 45 minutos, 1 e 2 horas são similares. Entretanto, independente do tempo, a preferência de A. argillacea entre os discos foliares variou com as linhagens de algodoeiro $\left(\mathrm{F}_{3.135}=\right.$ 16.79, $P<0.05)$. O genótipo menos preferido para alimentação foi Grandless (Figura 1). Tais resultados indicam que quantidades menores de glândulas de gossipol são deterrentes para alimentação do curuquerê em folhas de algodoeiro por produzirem menor número de substâncias voláteis atrativas para lagartas do inseto. Resultados semelhantes foram observados por Johnson (1984), onde constatou-se que as lagartas preferem se alimentar ao redor dos discos foliares, evitando-se contato com glândulas de gossipol. De acordo com Bottger et al. (1964), a menor densidade de lagartas e pupas está associada a resistência do tipo não-preferencial e antibiose. No entanto Vendramin (1984), não observou influência de glândulas de gossipol no desenvolvimento do curuquerê. 


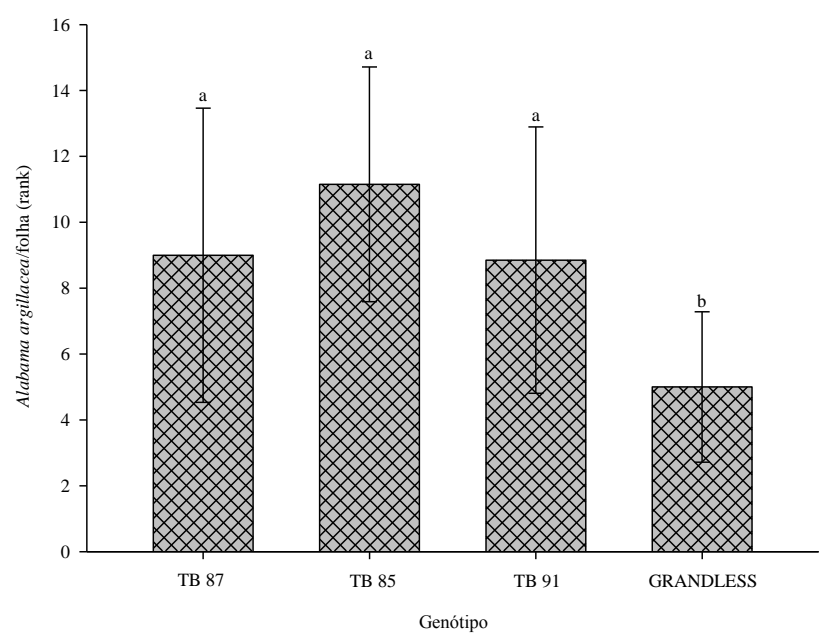

Figura 1 - Preferencia de Alabama argillacea por genótipos de algodoeiro. Ranks seguidos pela mesma letra não diferem pelo lsmean e teste Bonferroni $(P<0.05)$.

Raças primitivas com caracteres morfológicos como o gossipol, são menos susceptíveis a ataques de lepidópteros, podendo ser uma ferramenta em programas de manejo integrado de pragas, tornandose um método de controle ecológico e economicamente viável para o produtor.

Não ocorreu interação entre os ranks dos tratamentos e locais de permanências de insetos na placa de Petri $\left(\mathrm{F}_{6,99}=0.92, P=0.4819\right)$. Entretanto, verificou-se que o deslocamento de $A$. argillacea foi significativo após duas horas de exposição $\left(\mathrm{F}_{2,99}=\right.$ 75.64, $P<0.05$ ), sendo a linhagem Grandless a menos procurada pelos insetos.

Independente do genótipo ofertado com relação a permanência, verificou-se mais insetos sobre a folha do que próximo a folha ou centro da placa. De acordo com Carvalho (2016), os maiores índices de gossipol no limbo foliar, podem produzir substâncias voláteis atrativas a algumas pragas, auxiliando na localização de lavouras de algodão. Conforme referido no trabalho, as cultivares propícias a respectiva situação foram a Grandless e TB 87 pois possuem menor quantidade de gossipol no limbo foliar $\left(0,0\right.$ e 103, 88 glândulas de gossipol $/ \mathrm{cm}^{2}$ de folha). Isto indica que em condições de campo $A$. argillacea pode deslocar menos para genótipos com as referidas características, evidenciado a Grandless como promissora no manejo da praga.

Embora os insetos tiverem permanecido e preferidos os genótipos TB 75, TB 85, TB 87 e TB 91 a Grandless, não foi verificado diferenças entre o consumo alimentar após duas horas de exposição $\left(\mathrm{F}_{3,27}=1.70, P=0.1914\right)$. Este fato sugere que os insetos embora atraídos, foram inibidos, devido provavelmente a odores característicos dos genótipos. Azevedo et al. (2002), estudando comportamento alimentar de A. argillacea a genótipo de algodoeiro verificaram diferenças no consumo, entretanto eles também evidenciam a necessidades de se conhecer a composição química de folhas de plantas a serem ofertadas para insetos mastigadores.

\section{CONCLUSÕES}

As cultivares TB 87, TB 85 e TB 91 são mais atrativas a Alabama argillacea em mesmas condições de ataque, entretanto foram consumidas de forma similar. Sugere-se que trabalhos futuros levem em consideração a resposta de atratividade, mas estudem com maior acurácia a variável consumo alimentar em condições adversas aqui propostas.

Em condições de teste de chance de escolha, o genótipo menos preferido para alimentação foi Grandless. Todavia, estudos adicionais envolvendo outros genótipos bem como estádios larvais distintos de $A$. argillacea são necessários para melhor entendimento do comportamento alimentar da praga em condições campesinas.

\section{REFERÊNCIAS}

ALMEIDA, R. P.; DOMINGUES, C. A.; RAMALHO, F. S. Manejo Integrado de Pragas do Algodoeiro no Brasil. Embrapa Algodão, 2013, 59p. Disponível em: <http://www.cnpa.embrapa.br/aunidade/MIP_algodoeiro 2013.pdf>. Acesso: 24 mar. 2016.

AZEVEDO, F. R.; MATTOS, K. O.; VIEIRA, F. V. Comportamento alimentar de Alabama argillacea (Huebner, 1818) (Lepidoptera: Noctuidae) em algodoeiro. Ciência Agronômica, v.33, n.1, p.5-9, 2002.

BOTTGER, G. T.; SHEEHAN, E. T.; LUKEFAHR, M. J. Relation of gossypol content of cotton plants to insect resistance. Journal of Economic Entomology, v.57, n.2, p.283-285, 1964. 
CARVAlHO, C. F.; SOUZA, B. Potencial de insetos predadores no controle biológico aplicado. In: PARRA, J. R. P.; BOTELHO, P. S. M.; CORREAA-FERREIRA, B. S.; BENTO, J. M. S. (Eds.). Controle biológico no Brasil: parasitoides e predadores, São Paulo: Manole, 2002. p.191-208.

CARVALHO, L. P.; LUKEFAHR, M. J.; FARIAS, F. J. C.; VIEIRA, R. M.; MOREIRA, J. A. N.; COSTA, J. N. da. Seleção de algodoeiro com resistência ao bicudo. Pesquisa Agropecuária Brasileira, v.31, n.3, p.195-196, 1996.

CARVALHO, T. S. Mecanismos morfofisiológicos da resistência de raças primitivas de algodoeiros ao bicudo. 2016. 51f. Dissertação (Mestrado em Ciências Agrárias) - Universidade Estadual da Paraíba, Campina Grande.

EMBRAPA ALGODÃO. Cultura do Algodão no Cerrado. Embrapa Algodão, 2003. Disponível em: $<$ https://sistemasdeproducao.cnptia.embrapa.br/FontesHT ML/Algodao/AlgodaoCerrado/pragas.htm>. Acesso: 24 mar. 2016.

FERREIRA, A.; LARA, F. M. Tipos de resistência a Alabama argillacea (Huebner, 1818) (Lepidoptera: Noctuidae) envolvidos em genótipos de algodoeiro: II. Antibiose. Bragantia, v.58, n.2, p.287-292, 1999.

GALLO, D.; NAKANO, O.; SILVEIRA NETO, S.; CARVALHO, R. P. L.; BAPTISTA, G. C.; BERTI FILHO, E.; PARRA, J. R. P.; ZUCHHI, R. A.; ALVES, S.B.; VENDRAMIM, J. D.; MARCHINI, L. C.; LOPES, J. R. S.; OMOTO, C. Entomologia Agrícola. Piracicaba: FEALQ, 2002. 920p.

JOHNSON, S. J. Larval development, consumption, and feeding behavior of the cotton leafworm, Alabama argillacea (Hübner). The Southwestern Entomologist, v.9, n.1, p.1-6, 1984.

LARA, F. M.; FERREIRA, A.; CAMPOS, A. R.; SOARES, J. J. Tipos de resistência a Alabama argillacea (Huebner) (Lepidoptera: Noctuidae) envolvidos em genótipos de algodoeiro: I - não-preferência. Anais da Sociedade Entomológica do Brasil, v.28, n.4, p.739-744, 1999.
LARA, F.M. Princípios de resistência de plantas a insetos. 2. ed. São Paulo: Ícone, 1991. 336p.

MACEDO, L. P. M.; DA CUNHA, U. S.; VENDRAMIM, J. D. Gossipol: Fator De Resistência a Insetos-Praga. Campo Digital, v.2, n.1, p.34-42, 2007.

McAUSLANE, H. J.; ALBORN, H. T.; TOTH, J. P. Systemic induction of terpenoid aldehydes in cotton pigment glands by feeding of larval Spodoptera exigua. Journal of Chemical Ecology, v.23, n.12, p.2861-2879, 1997.

MIRANDA, J. E.; RODRIGUES, S. M. M.; ALBUQUERQUE, F. A.; SILVA, C. A. D.; ALMEIDA, R. P.; RAMALHO, F. S. Algodoeiro, identificação, pragas. 1. ed. Campina Grande, PB: Embrapa Algodão, 2015, 69p.

MONTANDON, R.; WILLIAMS, H. J.; STERLING, W. L.; STIPANOVIC, R. D.; VINSON, S. B. Comparision of the development of Alabama argillacea (Hübner) and Heliothis virescens (F.) (Lepidoptera: Noctuidae) fed glanded and glandless cotton leaves. Environmental Entomology. v.15, n.1, p.128-131, 1986.

SANTOS, T. M.; BOIÇA JÚNIOR, A. L. Resistência de genótipos de algodoeiro (Gossypium hirsutum L.) a Alabama argillacea (Hübner) (Lepidoptera: Noctuidae). Neotropical Entomology, v.30, n.2, p.297-303, 2001.

SAS System for Windows (Statistical Analysis System), versão 9.2. SAS Institute Inc, Cary, NC, USA. 2006.

VENDRAMIM, J. D. A resistência de plantas e o manejo de pragas. In: CROCOMO, W. B. (Ed.). Manejo de pragas. Botucatu: FEPAF, 1984. p.117-144. 